\title{
The Agent of Human Granulocytic Ehrlichiosis Resides in an Endosomal Compartment
}

\author{
Paul Webster, ${ }^{\star}$ Jacob W. IJdo, ${ }^{\ddagger}$ Linda M. Chicoine, ${ }^{\star}$ and Erol Fikrig ${ }^{\ddagger}$ \\ $*$ Department of Cell Biology and ${ }^{\ddagger}$ Department of Internal Medicine, Yale University School of Medicine, New Haven, Connecticut \\ 06520-8031
}

\begin{abstract}
The composition of cytoplasmic vacuoles containing the agent of Human Granulocytic Ehrlichiosis (HGE) was studied to investigate how this pathogen exists within infected host cells. Electron microscopy demonstrated that the HGE organism resides in a membrane-bound compartment within HL-60 cells: early forms of the HGE agent have a round reticular appearance while later structures are small and dense. Vacuoles containing HGE bacteria incorporated endocytosed colloidal gold particles, suggesting that they are part of the endocytic pathway. Antibodies directed to the mannose-6-phosphate receptor labeled vacuole membranes. Antibodies to the transferrin receptor and to the lysosomal membrane glycoprotein LAMP 1 did not. Moreover, 3-(2,4dinitroanilino)-3' -amino- $N$-methyldipropylamine, which normally accumulates in compartments with low $\mathrm{pH}$, was not present inside these vacuoles. These results suggest that vacuoles containing the agent of $\mathrm{HGE}$ fail to mature into phagolysosomes. We conclude that the agent of HGE appears to enter and modify part of the endocytic pathway. $(J$. Clin. Invest. 1998. 101:1932-1941.) Key words: Ehrlichia • intracellular pathogen $\bullet$ neutrophil $\bullet$ endosome $\cdot$ antibody
\end{abstract}

\section{Introduction}

Human Granulocytic Ehrlichiosis (HGE) $)^{1}$ is a newly recognized infectious disease of increasing importance in the United States and in Europe (1-8). The agent of HGE is an obligate intracellular pathogen that predominantly invades polymorphonuclear leukocytes and survives within membrane-bound phagosomes known as morulae. Based on similar 16S rDNA sequence comparisons, this pathogen is closely related to granulocytic Ehrlichia that infect horses (Ehrlichia equi) and sheep

Paul Webster and Jacob W. IJdo contributed equally to this work.

Address correspondence to Erol Fikrig, M.D., Section of Rheumatology, Department of Internal Medicine, Yale University School of Medicine, 604 Laboratory of Clinical Investigation, 333 Cedar Street, New Haven, CT 06520-8031. Phone: 203-785-2454; FAX: 203785-7053; E-mail: erol.fikrig@yale.edu

Received for publication 19 August 1997 and accepted in revised form 25 February 1998.

1. Abbreviations used in this paper: DAMP, 3-(2,4-dinitroanilino)-3'amino- $N$-methyldipropylamine; HGE, Human Granulocytic Ehrlichiosis; LAMP 1, lysosome-associated membrane protein 1; MPR, mannose-6-phosphate receptor; TfR, transferrin receptor.

J. Clin. Invest.

(C) The American Society for Clinical Investigation, Inc. 0021-9738/98/05/1932/10 \$2.00

Volume 101, Number 9, May 1998, 1932-1941

http://www.jci.org
(Ehrlichia phagocytophila) $(1,5)$. Transmission to man and other hosts occurs via Ixodes scapularis ticks (9) and, not surprisingly, HGE is found in areas where Lyme disease and babesiosis are common. Recently, the HGE agent has been cultured in the promyelocytic leukemia cell line, HL-60, facilitating investigation of this microbe (10).

Intracellular pathogens survive in host cells by using different strategies to evade destruction by lysosomal enzymes, including degradation of the vacuolar membrane and escape into the cytoplasm, blocking the fusion of the vacuole with lysosomes, and interference with vacuolar acidification (11-14). Studies of phagolysosome biogenesis suggest that plasma membrane receptors acquired during phagocytosis, such as transferrin receptor (TfR), are recycled back to the cell surface, while proteins characteristically associated with endocytic organelles, such as mannose-6-phosphate receptors (MPR) and lysosomal membrane proteins (LAMP), are incorporated in the phagolysosome membrane at subsequent stages (15). These active modifications of the phagosome membrane, stated here in an oversimplified form, help document the evolution of phagosomes into lysosomes, the end result of the endocytic pathway.

Pathogens influence vacuolar maturation in different ways (16). Mycobacterium tuberculosis phagosomes weakly label with antibodies to LAMP 1 but do not contain the vesicular proton ATPase, suggesting developmental arrest and no luminal acidification $(14,17)$. Toxoplasma gondii parasitophorous vacuoles are devoid of protein signals for fusion with endocytic organelles, and their absence results in the lack of membrane trafficking (18). Chlamydia trachomatis inclusions remain separate from the endocytic pathway, but acquire markers of the exocytic route $(19,20)$. In contrast, other organisms such as Listeria monocytogenes, Trypanosoma cruzi, and Rickettsiae disrupt the phagolysosomal membrane and escape into the cytoplasm $(11,12,21)$. Most Ehrlichia spp. and Anaplasma marginale (which are phylogenetically closely related organisms), do not leave the vacuolar compartment $(22,23)$. Ehrlichia risticii, which infects macrophages, inhibits the phagosome-lysosome fusion in vitro, and Ehrlichia chaffeensis selectively accumulate TfR, suggesting that they are localized in early endosomes $(24,25)$.

The agent of HGE is unique in that it appears to selectively persist in neutrophils in vivo-the first such pathogen to specifically choose this hostile environment in which to live. We hypothesized that the inhibition of the phagolysosomal development may be a likely mechanism by which HGE bacteria evade degradation within granulocytes. To investigate this, we examined HL-60 cells infected with HGE bacteria, using immunocytochemistry and electron microscopy.

\section{Methods}

Cultivation of the agent of HGE in HL-60 cells and purification. The promyelocytic cell line HL-60 (American Type Culture Collection 
240-CCL, Rockville, MD) was cultured in Iscove's modified Dulbecco's medium supplemented with $20 \%$ FBS and maintained at $37^{\circ} \mathrm{C}$ with $5 \%$ carbon dioxide. Blood was obtained from mice infected with the HGE bacterial isolate NCH-1 (26) and incubated under sterile conditions with $10 \mathrm{ml}$ of HL-60 cells with a density of $10^{6}$ cells $/ \mathrm{ml}$ in $70 \mathrm{ml}$ culture flasks, as described (10). Cell density was maintained between $0.5 \times 10^{6}$ and $1.5 \times 10^{6}$ cells $/ \mathrm{ml}$ by changing culture medium twice a week. Usually, $5 \mathrm{ml}$ of the culture was removed and an equal amount of fresh medium was added. If the cell count was below $0.5 \times$ $10^{6}$ fresh HL-60 cells were added to a final concentration of $10^{6}$ cells/ $\mathrm{ml}$. Slides of HGE organism-infected HL-60 cells for light microscopy were air-dried, stained with Diff-Quick (Baxter Healthcare Corp., Miami, FL) and examined for morulae. For immunofluorescence and electron microscopy, infected HL-60 cells were pelleted at 2,000 rpm for $10 \mathrm{~min}$ and resuspended using a 21-gauge needle to disrupt the HL-60 cells, releasing free HGE organisms into the supernatant. The supernatant was subsequently spun at 3,000 rpm for $10 \mathrm{~min}$ to pellet intact HL-60 and nuclear debris. The HGE agent-containing supernatant was then used to infect fresh HL-60 cells. At different time points cultures were harvested by gently pelleting the infected cells for further use in immunofluorescence and electron microscopy studies.

HGE organisms were purified using renografin density gradient centrifugation as described $(27,28)$ with some modifications. Briefly, cultures with $60 \%$ or more infected HL-60 cells were centrifuged and resuspended in PBS-glucose. HL-60 cells were then lysed by shearing using a 21-gauge needle and after pelleting cellular debris at 2,000 rpm for $10 \mathrm{~min}$, the supernatant was collected and incubated with RNase and DNase (final concentration $50 \mu \mathrm{g} / \mathrm{ml}$ ) for $45 \mathrm{~min}$. Using renografin with a noncontinuous gradient of $42-30 \%$ (Hypaque 76; Nycomed Inc., New York, NY) ultracentrifugation was performed at $22,000 \mathrm{rpm}$ for $75 \mathrm{~min}$ at $4^{\circ} \mathrm{C}$ in a swing bucket rotor (Beckman Instruments, Inc., Fullerton, CA). The interface band was collected in a sterile pipette and dissolved in SPGN $\left(7.5 \%\right.$ sucrose, $3.7 \mathrm{mM} \mathrm{KH}_{2} \mathrm{PO}_{4}, 7 \mathrm{mM}$ $\mathrm{K}_{2} \mathrm{HPO}_{4}$, and $5 \mathrm{mM} \mathrm{L}$-glutamine), pelleted at 13,000 and resuspended in SPGN at a concentration of $2 \mu \mathrm{g} / \mu \mathrm{l}$ and stored at $-70^{\circ} \mathrm{C}$.

Antibodies. Antibodies to the HGE agent were produced by immunizing rabbits with a lysate of purified HGE organisms in complete Freund's adjuvant and boosted three times with the same preparation in incomplete Freund's adjuvant at 2-wk intervals as described previously (29). Before immunization, lysate was dialyzed against PBS and heat treated at $56^{\circ} \mathrm{C}$. For each immunization $30 \mu \mathrm{g}$ of purified heat-killed lysate was injected subcutaneously. Also, antibodies to the $\mathrm{HGE}$ agent were produced in $\mathrm{C} 3 \mathrm{H}$ mice by inoculating $50 \mu \mathrm{l}$ of infected blood, containing live $\mathrm{NCH}-1$, from an infected and parasitemic $\mathrm{C} 3 \mathrm{H}$ mouse. Mice were killed $21 \mathrm{~d}$ after inoculation and plasma was recovered and stored at $-20^{\circ} \mathrm{C}$ for immunolabeling studies. The rabbit anti-Ehrlichia antibodies were tested for cross-reactivity with HL-60 cells, but this was not detected at the dilutions tested (1:25-1:10,000). Intracellular organelles of infected host cells were probed on thawed cryosections with rabbit anti-chicken cationdependent MPR (gift from Bernard Hoflack, EMBL, Heidelberg, Germany), antibodies to LAMP 1 (Hybridoma Bank, Iowa City, Iowa) and mouse anti-human TfR (mAb OKT9; Ortho Diagnostic, Paris, France). Intracellular 3-(2,4-dinitroanilino)-3'-amino- $N$-methyldipropylamine (DAMP) was visualized using specific polyclonal antibodies to dinitrophenol (anti-DNP; gift from I. Mellman, Yale University School of Medicine, New Haven, CT). Protein A-gold was produced by and purchased from J.W. Slot (Utrecht University, The Netherlands). Unconjugated and conjugated secondary antibodies were purchased from ICN Pharmaceuticals (Costa Mesa, CA).

Detection of organelles with low $\mathrm{pH}$ in living cells. The visualization of low $\mathrm{pH}$ organelles within HGE-infected and uninfected HL60 cells was performed using the ability of these compartments to accumulate acridine orange. Living cells were incubated in medium containing $0.005 \%$ acridine orange (Molecular Probes, Inc., Eugene, OR) for $10 \mathrm{~min}$ at $37^{\circ} \mathrm{C}$. Accumulated acridine orange in living cells was visualized by epi-fluorescent illumination using an Axioplan light microscope (Zeiss, Oberkochen, Germany).
Double immunofluorescence labeling. For double labeling studies, semi-thin cryosections of $0.5 \mu \mathrm{m}$ were washed twice in PBS, then washed in PBS- $0.1 \%$ glycine and then PBS- $10 \%$ FBS for 5 min each, and then incubated with the murine anti-human TfR or rabbit antihuman MPR (at dilutions of 1:25 or 1:50, respectively) for $30 \mathrm{~min}$. Sections were then washed with PBS three times for 5 min each, and incubated with TRITC-conjugated anti-mouse antibodies or FITCconjugated anti-rabbit antibodies at dilutions of 1:25 and 1:100, respectively. After three PBS washes, the sections were incubated with rabbit anti-Ehrlichia or mouse anti-Ehrlichia antibodies (at dilutions of 1:50 or 1:25, respectively) and then washed. Slides were then incubated with FITC-conjugated anti-rabbit or TRITC-conjugated antimouse antibodies, washed and mounted on glass slides with semi-permanent mounting medium consisting of $13 \%$ polyvinyl alcohol (Mowiol; Calbiochem Corp., La Jolla, CA) and 30\% glycerol in $0.15 \mathrm{M}$ Tris-HCL ( $\mathrm{pH} 8.5)$ and examined by epi-fluorescent illumination with an Axiophot light microscope (Zeiss).

Endocytosis of colloidal gold by infected cells. Colloidal gold particles with a $5 \mathrm{~nm}$ mean particle size, prepared as described previously $(30,31)$ were coupled to BSA by adding $2.4 \mathrm{mg} / \mathrm{ml}$ of gold sol at $\mathrm{pH}$ 6.0 . The gold probe (BSA-gold), concentrated by centrifugation, dialyzed and then suspended in Dulbecco's MEM containing 5\% FCS, was added to infected HL-60 cells at a concentration where the final OD of the gold sol was four at $525 \mathrm{~nm}$ and was incubated at 13 or $37^{\circ} \mathrm{C}$. After increasing times, the gold suspension was removed and the cells were fixed for electron microscopy.

Electron microscopy. For routine morphological examination, cell suspensions were fixed in $2.5 \%$ glutaraldehyde in $100 \mathrm{mM}$ sodium cacodylate ( $\mathrm{pH} 7.4)$, pelleted, post-fixed in osmium tetroxide, en bloc stained in $1 \%$ uranyl acetate in $50 \mathrm{mM}$ sodium maleate ( $\mathrm{pH}$ 5.2), and dehydrated in ethanol and embedded in epoxy resin. Ultrathin sections, stained with uranyl acetate and lead citrate, were examined and photographed in an EM410 transmission electron microscope (Philips Electronic Instruments, Mahwah, NJ) operating at $80 \mathrm{kV}$.

For immunocytochemistry, some cell suspensions were fixed for $1 \mathrm{~h}$ in $0.5 \%$ glutaraldehyde buffered in $100 \mathrm{mM}$ sodium phosphate ( $\mathrm{pH}$ 7.4). Other cells were fixed for $1 \mathrm{~h}$ in $4 \%$ formaldehyde, in 100 $\mathrm{mM}$ phosphate buffer, and then left overnight in $8 \%$ formaldehyde in the same buffer. The fixed, loose cells were embedded in $10 \%$ gelatin, infused in $2.3 \mathrm{M}$ sucrose, frozen on aluminum specimen pins by immersion in liquid nitrogen and sectioned on an Ultracut E ultramicrotome with FCS cryo-unit (Leica, Inc., Deerfield, IL) at temperatures of -110 to $-130^{\circ} \mathrm{C}$ using glass or diamond knives (Diatome US, Ft. Washington, PA). Sections were handled and immunolabeled using established methods (32). Briefly, the sections were retrieved using sucrose or methyl cellulose droplets (33), mounted onto coated specimen grids, labeled with primary antibodies, unconjugated bridging antibodies (when appropriate), protein A-gold, and finally contrasted by incubating and drying in the presence of a 9:1 mixture of $2 \%$ aqueous methyl cellulose and $3 \%$ aqueous uranyl acetate (final concentration of $0.3 \%$ uranyl acetate). To prevent possible nonspecific binding (a phenomenon observed with the rabbit anti-rat bridging antibodies), all antibodies specific for mammalian proteins and DNP were preincubated in a homogenate of purified HGE bacteria before being applied to sections.

Incubation of cells with DAMP was performed according to the method described previously (34). The HL-60 cells were incubated in Dulbecco's MEM containing $10 \%$ FCS and $30 \mu \mathrm{m}$ DAMP at $37^{\circ} \mathrm{C}$. After 30 min the cells were washed three times with warm Dulbecco's MEM to remove free DAMP and then fixed in $0.5 \%$ glutaraldehyde in $100 \mathrm{mM}$ sodium phosphate buffer ( $\mathrm{pH}$ 7.4). Accumulated DAMP was detected by applying anti-dinitro phenol (DNP) antibodies and protein A-gold to cryosections through these cells.

Morphometry. Quantitation of results followed unbiased, sequential sampling protocols (35). For estimates of antibody colocalizations (anti-MPR with HGE label), random micrographs of fluorescent-labeled cells were obtained on black and white film using an Axiophot microscope (Carl Zeiss, Inc., Thornwood, NY) and com- 
pared. Regions of cells that were positive for anti-HGE were examined for MPR labeling and scored either as positive or negative. A total of 130 morulae were examined and scored.

Estimates of the volume density of HGE in the total enclosing vacuole volume were performed using established methods (36). The estimates were obtained from point counts of L100 cross-lattice grids overlaid onto electron micrographs of random, sequentially sampled morulae. At each time point, a total of 100 phagosomes were scored.

The percentage of HGE-containing vacuoles that also contained endocytosed BSA-gold particles was estimated by random sequential sampling thin sections of resin-embedded cells by electron microscopy. A mean of 100 morulae were sampled for each experimental condition.

\section{Results}

We first examined the temporal development of HGE bacteria-containing vacuoles in HL- 60 cells at $0,1,3$, and $6 \mathrm{~h}$ and 1 , $2,3,5$, and $7 \mathrm{~d}$ after infection. Discrete morulae were first identified at $2 \mathrm{~d}$ but not at earlier time points (not shown). By light microscopy, these morulae increased in number until by $5 \mathrm{~d}$, when $60 \%$ of the cells were infected, at which time infected cells became fragile and fragmented. At $7 \mathrm{~d}$ a majority of the infected cells had lysed (not shown).

Examination by electron microscopy showed that the cells contained HGE organisms with two different morphologies.
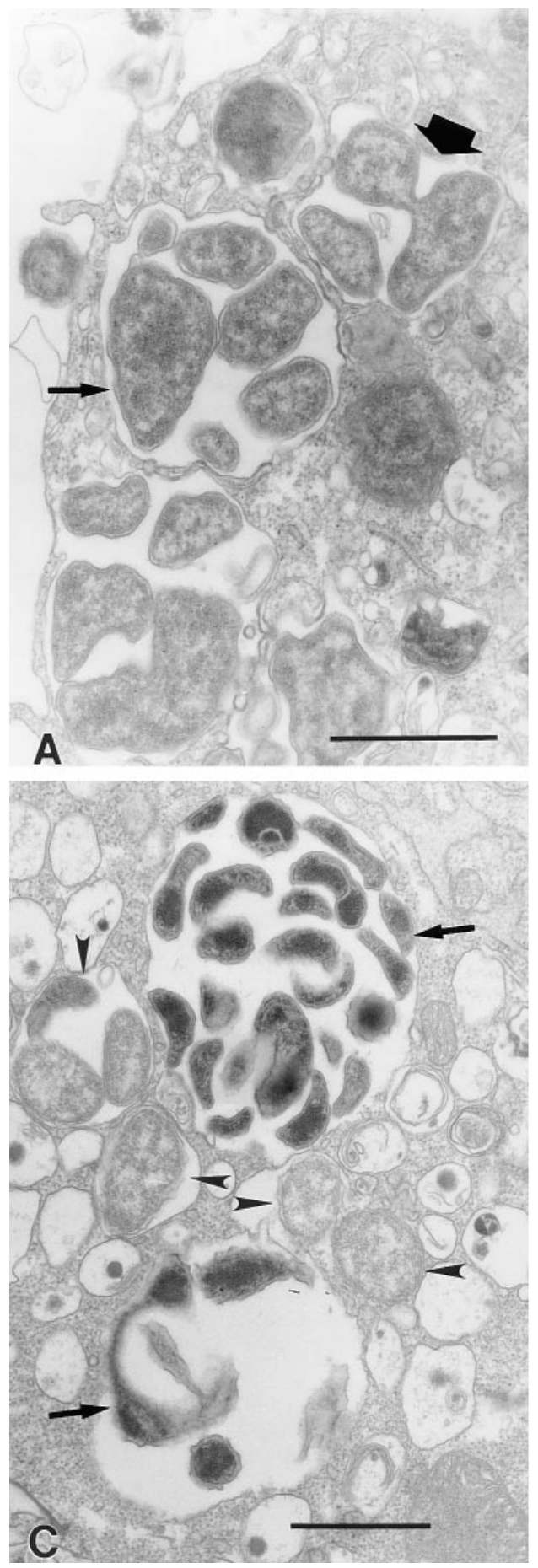
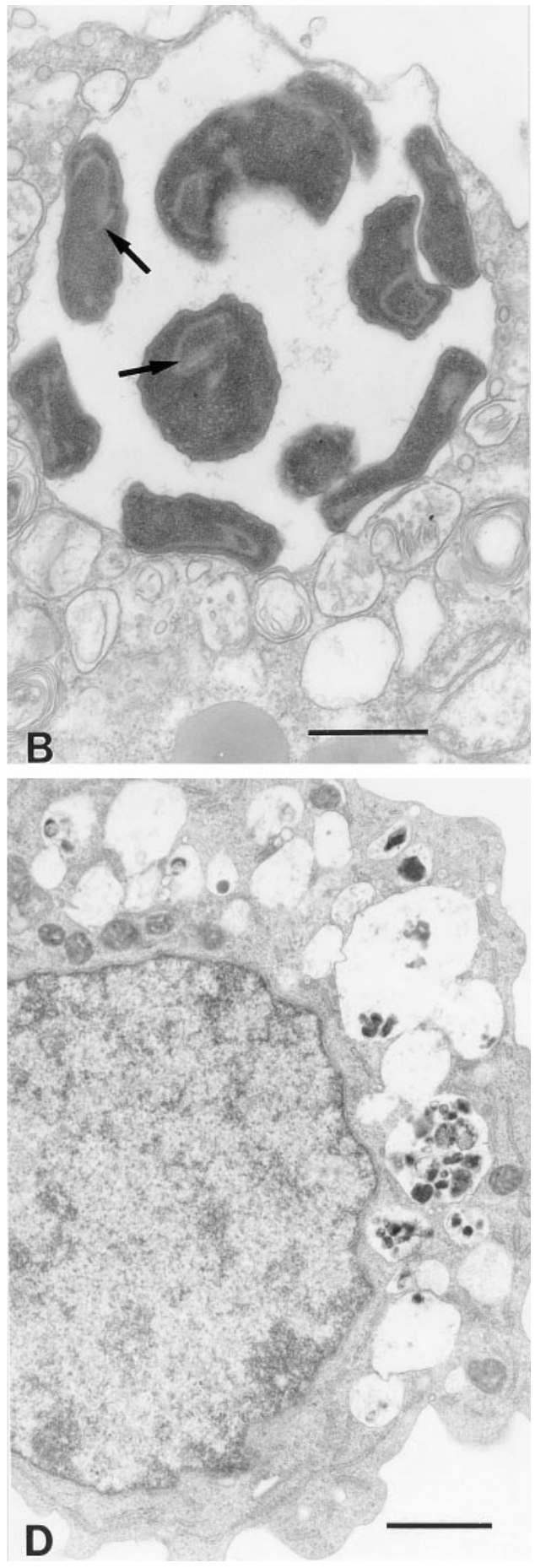

Figure 1. Sections through epoxy resin-embedded HL-60 cells infected with HGE bacteria showing organisms in vacuoles with two distinct morphologies. $(A)$ During the early stages of infection the Ehrlichia have a loose, spheroid appearance (small arrow). Binary fission is evident within one vacuole (large arrow). (B) Other Ehrlichia are more angular and their cytoplasm electron opaque. Within these angular structures there are what appear to be intracellular membranes ( $a r$ rows). (C) Infected cells often contain intracellular HGE bacteria with both morphological types, sometimes within the same vacuole (left arrow head). In this example, the large vacuoles containing dense organisms (arrows) are in close proximity to other vacuoles containing the HGE agent with a spheroid appearance (arrowheads). (D) Neither of these intracellular inclusions are observed in uninfected HL-60 cells. Scale bars, $1 \mu \mathrm{m}$. 
Table I. Volume Densities (Vv) of HGE-bacteria in Phagosomes

\begin{tabular}{lcccc}
\hline $\begin{array}{l}\text { Days after } \\
\text { infection }\end{array}$ & $\begin{array}{c}\text { Vv (total HGE } \\
\text { in phagosome) }\end{array}$ & $\begin{array}{c}\mathrm{Vv} \\
\text { (light stage) }\end{array}$ & $\begin{array}{c}\mathrm{Vv} \\
\text { (dense stage) }\end{array}$ & $\begin{array}{c}\text { Ratio } \\
\text { (Vv light/Vv dense) }\end{array}$ \\
\hline 2 & $0.74( \pm 0.03)$ & $0.53( \pm 0.05)$ & $0.21( \pm 0.05)$ & 2.5 \\
4 & $0.54( \pm 0.03)$ & $0.35( \pm 0.04)$ & $0.19( \pm 0.03)$ & 1.8 \\
6 & $0.50( \pm 0.02)$ & $0.36( \pm 0.03)$ & $0.14( \pm 0.03)$ & 2.6
\end{tabular}

Micrographs of phagosomes containing HGE-organisms, obtained by sequential random sampling, were examined using cross-lattice overlays. The Vv of HGE bacteria within phagosomes, and Vv of the two different developmental stages of the agent of HGE with phagosomes, were estimated using point counting methods (with standard error).

Structures with spheroid shapes and relatively diffuse cytoplasm were found in infected cells, enclosed within membranebound organelles (Fig. $1 A$ ). Some HGE bacteria also had irregular and angular profiles with cytoplasm that was more electron opaque (Fig. $1 \mathrm{~B}$ ). Within these denser structures profiles with a morphology similar to membranes were observed (Fig. $1 B$ ). Many of the infected cells contained organisms showing both morphologies (Fig. $1 C$ ) that were sometimes seen within the same vacuole (Fig. $1 C$ ). Neither of these intracellular structures were found in uninfected HL-60 cells (Fig. 1 D) and indirect immunofluorescence assay (IFA) using HGE bacteria-antisera (not shown) confirmed that these were morulae containing the agent of HGE.

Volume density measurements of HGE organisms within the enclosing vacuoles were performed at different time points during infection (Table I). These estimates were designed to evaluate the total volume of phagosome occupied by the HGE organisms as well as the proportion of each developmental stage within phagosomes. At early stages of infection (day 2), the HGE agent occupied most of the vacuole volume (74\%). At later stages of infection (days 4 and 6), the volume density of the HGE organisms within the vacuole had been reduced to 54 and $50 \%$, respectively. Volume density measurements of the two different forms of the HGE agent (spheroid versus dense) revealed that the spheroid forms occupied approximately twice the volume of the phagosome volume than did the dense forms. At day 4 of infection, the volume density of spheroid forms $(35 \%)$ as compared with the irregular, dense forms (19\%) was reduced (ratio of 1.8), suggesting that the developmental process progresses from spheroid to dense forms. By day 6 of infection the ratio of spheroid to dense forms had again increased to 2.6. With asynchronous cultures of pathogens able to re-infect cells within the population this increase in early forms is not surprising.

Intracellular changes in morphology of the HL-60 cells appeared as a result of infection with HGE bacteria. The cytoplasm became more electron lucent (Fig. $2 A$ ). The endoplasmic reticulum, especially where it becomes the nuclear envelope, was distended (Fig. 2 B). In cells that had lost normal cytoplasmic appearance and where intracellular membrane organization had been disrupted, Ehrlichia-containing vacuoles were seen in close proximity to the host plasma membrane (Fig. $3 A$ ). In some instances the membranes of these vacuoles were broken, exposing their contents to the outside of the cells (Fig. $3 \mathrm{~B}$ ). More often in pellets of cells infected for more than $5 \mathrm{~d}$, the Ehrlichia were seen enclosed by membranes and surrounded by cell debris (Fig. $3 \mathrm{C}$ ). In some infected cells, the Ehrlichia were also seen clustering around unidentified structures found within the same vacuole (Fig. $4 A$ ) or associated with the vacuole membrane, within the cell cytoplasm (Fig. $4 B$ ).

Because HGE bacteria were released into the extracellular milieu after lysis of the cells, we then examined how the organisms interacted with the surface of other HL-60 cells. An extracellular association of the HGE bacteria with HL-60 cells
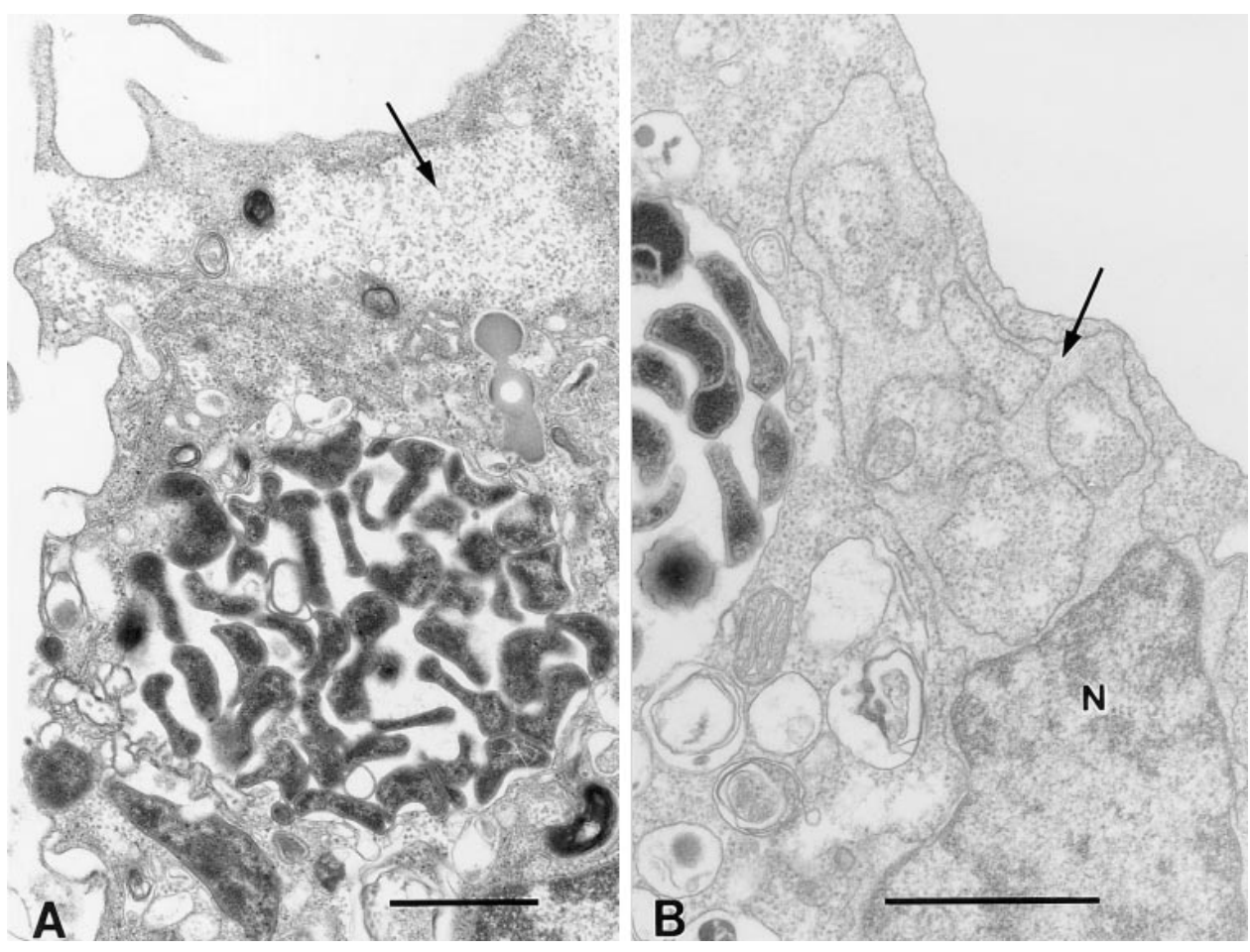

Figure 2. Sections through resinembedded cells showing changes of infected host cells. $(A)$ The cytoplasm of infected cells become more translucent in places (arrow). (B) The nuclear envelope is distended (arrow). Scale bars, $1 \mu \mathrm{m}$. 

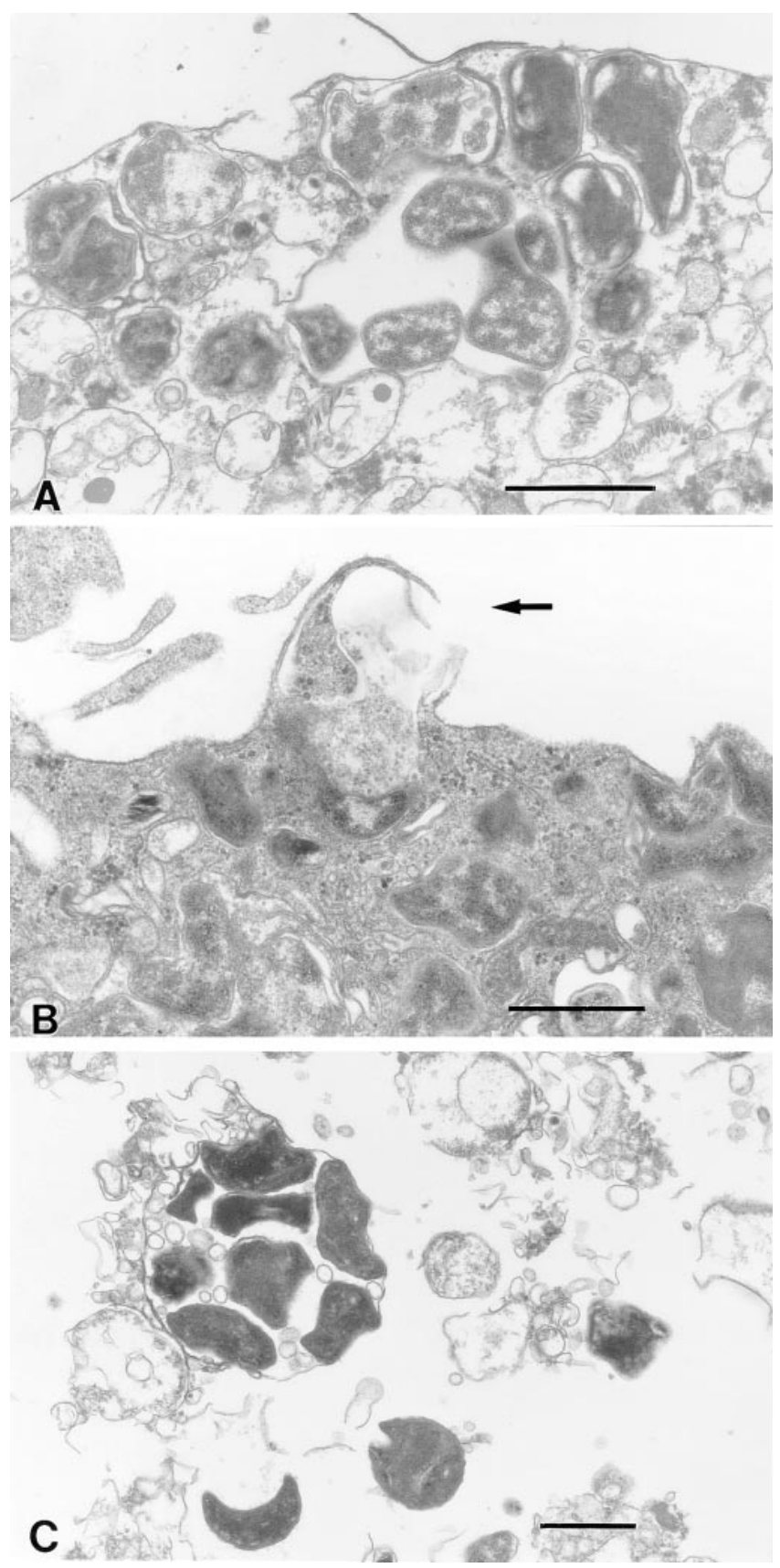

Figure 3. Sections through resin-embedded cells showing changes during the later stages of infection. $(A)$ During the later stages of infection HGE bacteria-containing vacuoles are seen in close proximity to the host plasma membrane. This micrograph also shows that the normal cytoplasmic and membrane organization of the host cell has been disrupted. (B) Occasionally vacuoles are broken open (arrow), suggesting release of the vacuole contents into the extracellular medium. (C) More often, Ehrlichia enclosed within membranes are seen surrounded by cell debris. Scale bars, $1 \mu \mathrm{m}$.

was observed (Fig. 5). Ehrlichia with both morphologic characteristics were found in close proximity to host cell plasma membrane (Fig. $5 \mathrm{C}$ ) and in some instances, this association appeared as a tight pathogen-host cell interaction (Fig. 5, A and $B$ ).

To investigate whether the morulae were accessible from the endocytic pathway, Ehrlichia-infected HL-60 cells were incubated in the presence of BSA-gold for $60 \mathrm{~min}$ at $37^{\circ} \mathrm{C}$. Subsequent examination of these cells by transmission electron microscopy showed colloidal gold particles within membranebound organelles inside the cells. Small amounts of gold particles were also seen in some Ehrlichia-containing vacuoles (Fig. $6 \mathrm{~A}$ ). Gold particles were detected in some morulae, indicating that at least some of the Ehrlichia-containing morulae are part of the endocytic pathway. To investigate the dynamics of BSAgold entry into the Ehrlichia-containing vacuoles, infected and uninfected HL-60 cells were incubated with BSA-gold at 13 and $37^{\circ} \mathrm{C}$. Samples were taken at $0,30,60$, and $120 \mathrm{~min}$ for analysis. At $0 \mathrm{~min}$, there was no BSA-gold found in the Ehrlichia-containing vacuoles, while at 30, 60, and 120 min BSAgold had entered 20,43 , and $28 \%$ of the morulae, respectively (Fig. 7). In the cells incubated at $13^{\circ} \mathrm{C}$ only $13 \%$ of the morulae contained any BSA-gold after $60 \mathrm{~min}$. The number of morulae present in the cells after 120 -min incubation at $13^{\circ} \mathrm{C}$ were so few that an accurate estimation of the BSA-positive vacuoles was not possible. Infected and uninfected HL-60 cells contained BSA-gold in similar amounts (data not shown).

Next, we examined the vacuoles for markers specific to the endocytic pathway to further delineate the characteristics of the morulae. Cryosections through cells were labeled with antibodies to MPR and LAMP 1 and examined by electron mi-
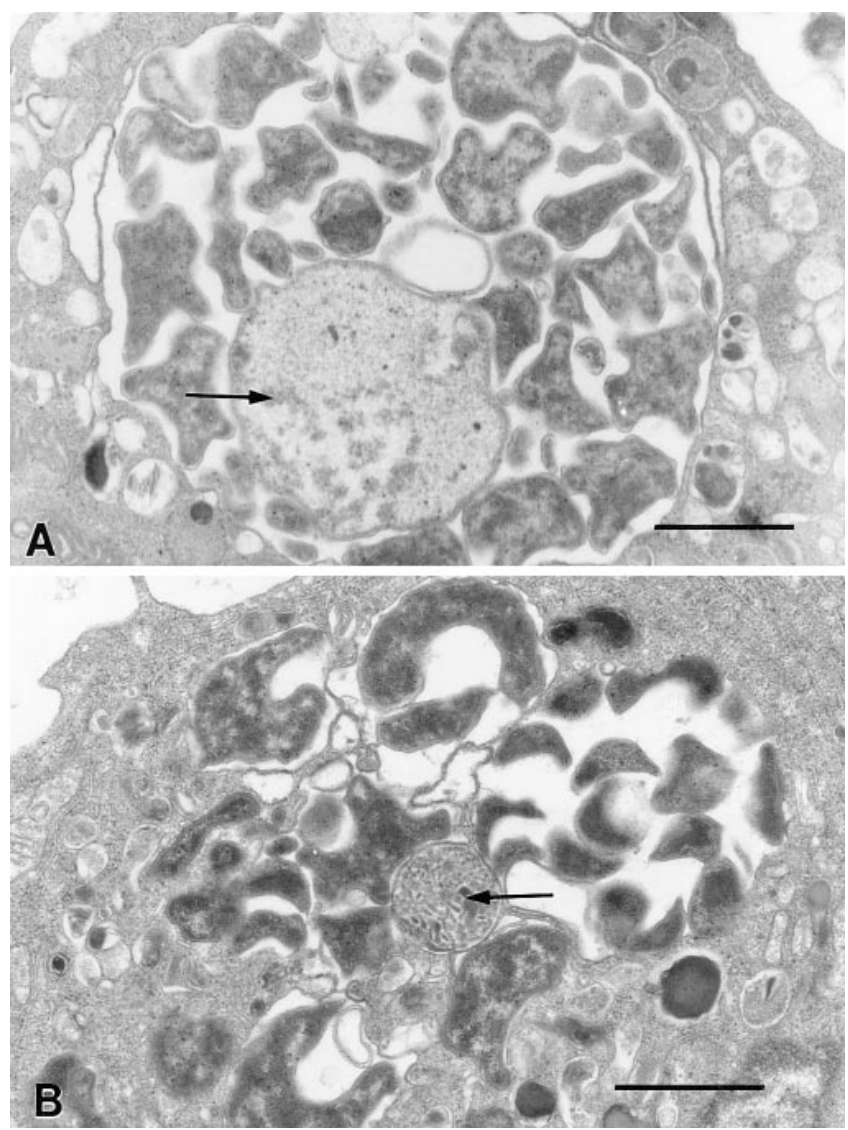

Figure 4. Resin-embedded cells showing structures associated with the intracellular HGE bacteria. $(A)$ Large cytoplasmic structures with circular profiles (arrow), can be observed within HGE agent-containing vacuoles. (B) Similar structures (arrow) are in close proximity to but not enclosed by Ehrlichia-containing vacuoles. Scale bars, $1 \mu \mathrm{m}$. 


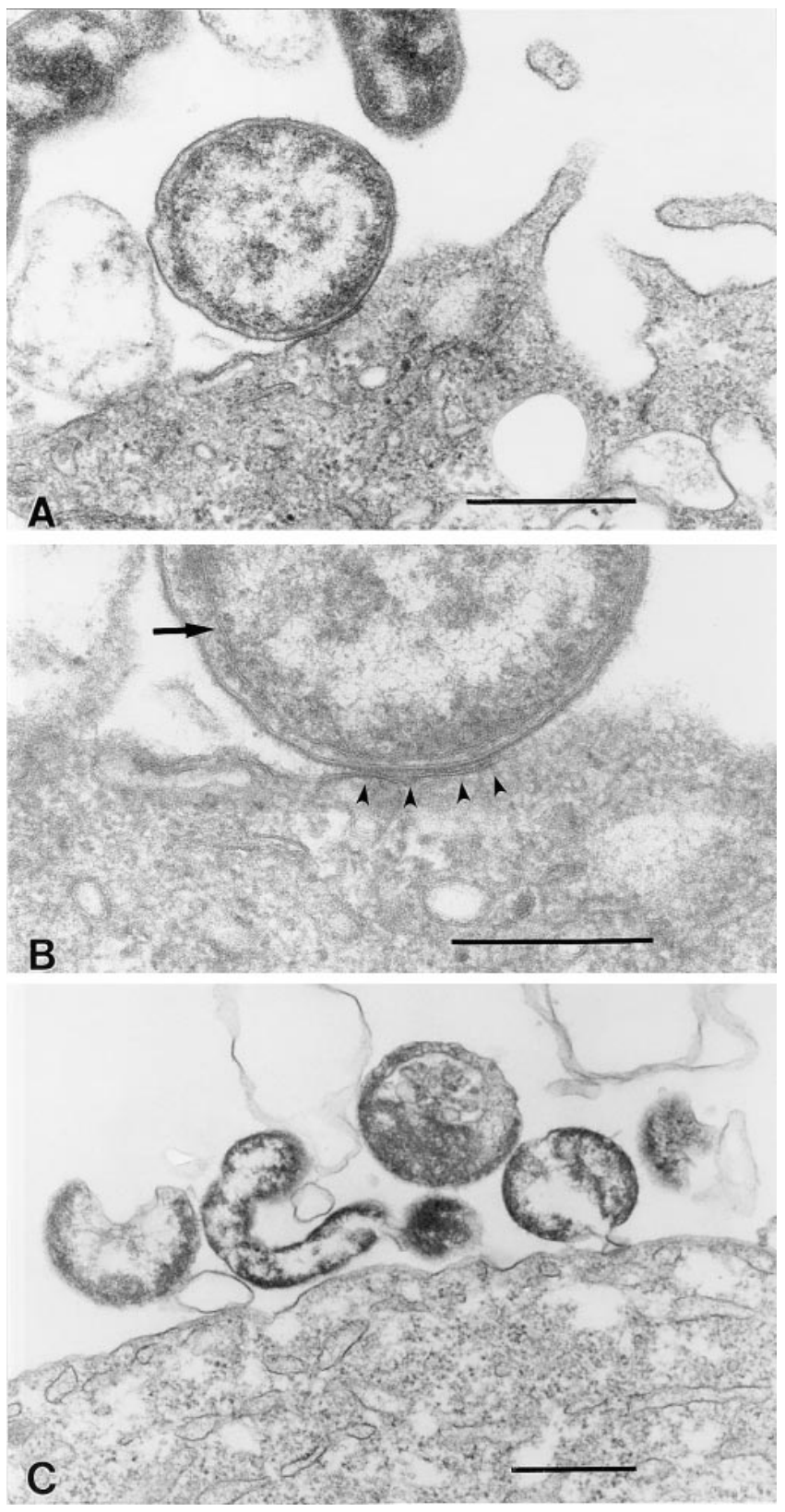

Figure 5. Sections through resin-embedded cells showing the association of extracellular HGE bacteria with host cell membranes. $(A)$ Spheroid particles attached to the host plasma membrane. $(B)$ Higher magnification reveals a close apposition of the HGE agent and host cell membranes (arrowheads). Structures resembling membranes are present in this loose, spheroid shaped organism (arrow). (C) Loose attachment of Ehrlichia with the angular appearance can also be seen. Scale bars, $1 \mu \mathrm{m}$.

croscopy. The MPR antibodies, in addition to labeling HL-60 cell organelles, showed reactivity with the membranes of some of the HGE bacteria-containing vacuoles (Fig. $6 \mathrm{~B}$ ). The LAMP 1 antibodies labeled many intracellular membranes, most of which were in close proximity to the Ehrlichia-containing vacuoles (Fig. $6 C$ ). However, LAMP 1 labeling of the Ehrlichia-containing vacuole membrane was not detected on any of the sections examined ultrastructurally.

To further investigate the properties of the morulae, we ex- amined infected cells for the presence of organelles with low lumenal $\mathrm{pH}$, as is the case for mature phagolysosomes, by their ability to accumulate DAMP. The DAMP, visualized using anti-DNP antibodies, accumulated in structures that were in close proximity to the Ehrlichia-containing vacuoles (Fig. 6D). DAMP was not identified however, within the morulae. Some gold labeling was seen within the HGE organisms themselves, suggesting that the bacterial cytoplasm-but not the vacuolehad a low $\mathrm{pH}$. This result implies that acidification of the Ehrlichia-containing vacuole does not occur.

Although DAMP contains many lysine residues to allow for immobilization using aldehyde cross-linking, it was possible that accumulated DAMP was being washed away from the large volume of the morulae. To discount this possibility, living cells, both infected and uninfected were incubated in the presence of acridine orange. This compound, like DAMP, passes freely across membranes until encountering low $\mathrm{pH}$ compartments, where it accumulates. This accumulation can be easily seen by fluorescence microscopy as discrete areas of bright orange fluorescence. In uninfected cells, the acridine orange accumulated in peri-nuclear regions and appeared to be in vacuolar structures of variable diameter (data not shown). Cells infected with HGE showed an accumulation of acridine orange in structures similar to those observed in the uninfected cells. Additionally, the acridine orange accumulated within the HGE organisms but not within the enclosing vacuole (Fig. 8).

The data using the anti-MPR antibodies indicated that some HGE-containing vacuoles labeled with the anti-MPR antibodies but others did not. Due to the small, thin samples obtained for electron microscopy, this result could be interpreted to mean that either the labeling with anti-MPR was localized to part of all vacuoles, or that only a proportion of the vacuoles contained the MPR. To sample a larger portion of the total population of infected HL-60 cells, we examined the labeling pattern of the MPR antibody by light microscopy. Semi-thin sections through infected cells were double labeled with antibodies to Ehrlichia organisms and to MPR. Examination of these sections by light microscopy revealed a partial colocalization of these markers. Some structures that labeled with the anti-Ehrlichia antibodies also labeled with the anti-MPR, but others did not (Fig. 9). A quantitative estimation of the level of colocalization of anti-Ehrlichia antibodies with the anti-MPR antibodies showed that there was colocalization with MPR positive structures in $68 \%$ of the Ehrlichia-containing vacuoles. This observation is in agreement with our immunocytochemical data, which rule out the possibility that extracellular Ehrlichia were being identified as MPR negative by light microscopy. To further characterize the vacuole membrane containing the Ehrlichia, we probed sections through infected cells with antibodies to the human TfR (OKT9). Although we were unable to produce a satisfactory signal for electron microscopy, we were able to detect this antibody by light microscopy. We did not detect colocalization of the anti-Ehrlichia and anti-TfR antibodies (Fig. 10). This suggests that the HGE pathogen does not reside in early endosomes or transferrin recycling compartments.

\section{Discussion}

In this study we examine the intracellular stages of the HGE agent by transmission electron microscopy and immunocytochemistry. We examine the morphology of the HGE agent 

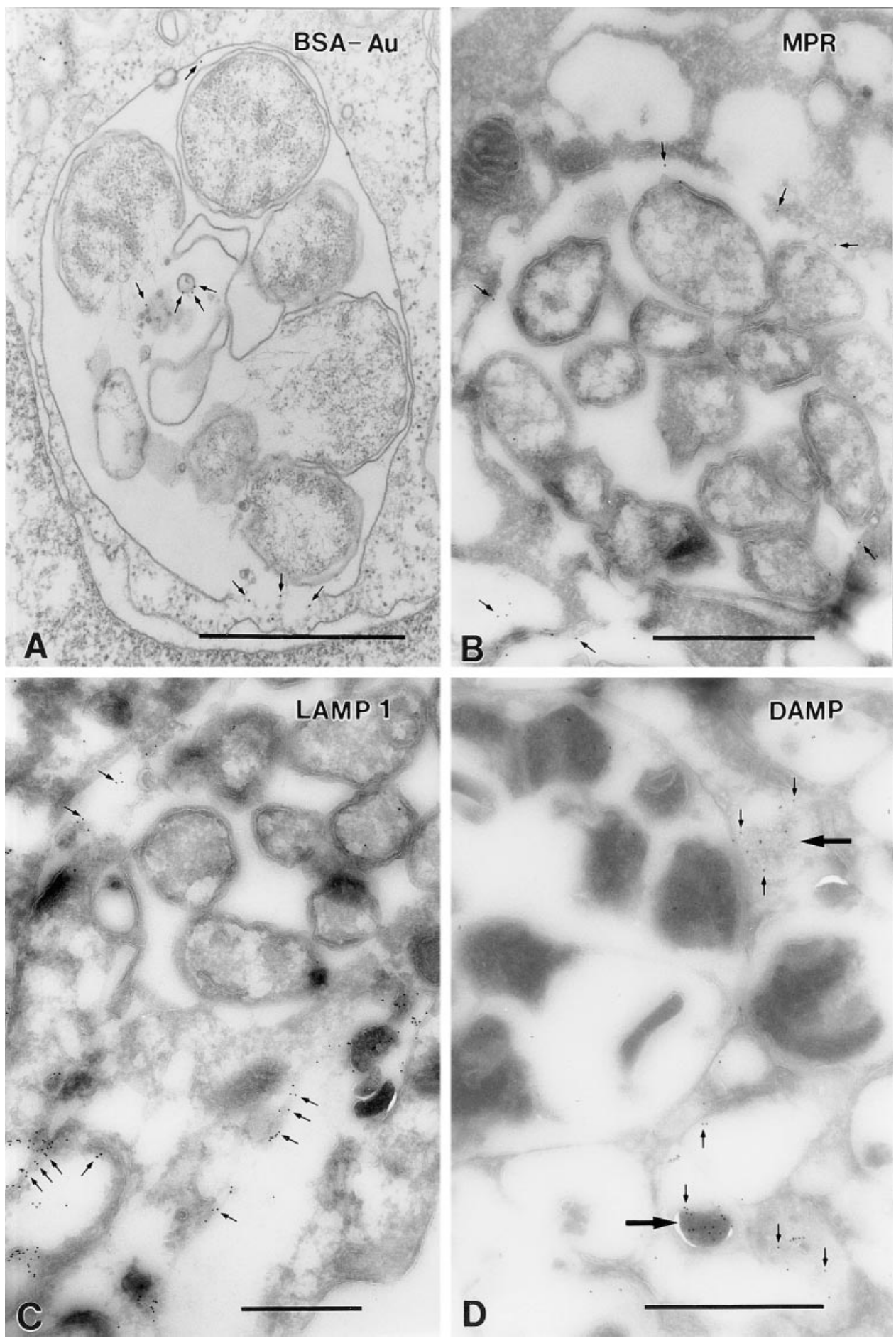

Figure 6. Electron micrographs of Ehrlichia-infected HL-60 cells. (A) Section through an Ehrlichiainfected HL-60 cell incubated with BSA-gold for $1 \mathrm{~h}$ at $37^{\circ} \mathrm{C}$. Some endocytosed colloidal gold particles (arrows) are present within the HGE-containing vacuole. $(B)$ Thawed, thin cryosection through Ehrlichia-infected HL-60 cells and labeled with antibodies to MPR. A small amount of labeling is detected on the membrane enclosing the agent of HGE (arrows). (C) Cryosection labeled with antibodies to LAMP 1 showing the antigen on membranes in close apposition to the vacuole containing the HGE bacteria (arrows). There is no LAMP 1 labeling on the vacuole membrane. $(D)$ Cryosection through a cell incubated in the presence of DAMP before fixation. This section shows small structures, close to the vacuole with HGE bacteria, that have accumulated DAMP (large arrows). The DAMP was visualized using anti-DNP antibodies and protein A-gold (small arrows). Although protein A-gold particles are occasionally seen within the HGE bacteria (not shown), DAMP is not evident in the lumen of the HGE organisms-containing vacuole. Scale bar, $1 \mu \mathrm{m}$. within HL-60 cells and show some unique characteristics of this organism. Intracellular pathogens either remain within membrane-bound organelles or escape into the cytoplasm after entering the host cell. We show that the agent for HGE selectively persists within granulocytes and remains confined to a membrane-bound vacuole. There was no evidence to suggest that the HGE organisms were able to disrupt the enclosing phagosome membrane to gain access to the host cell cytoplasm. Additionally, we show that the HGE agent resides in organelles that are part of the endocytic pathway. We arrived at this conclusion because endocytosed BSA-gold was found in
Ehrlichia-containing vacuoles and the enclosing membrane of these vacuoles labeled with antibodies to the MPR, a known marker for endocytic organelles. Interestingly, not all of the Ehrlichia-containing vacuoles labeled with this antibody. Furthermore, the vacuole membrane did not label with antibodies to LAMP 1 or TfR, which are markers for late and early endocytic compartments, respectively. The vacuole was not able to accumulate DAMP, nor acridine orange, suggesting that the vacuole lumen did not have a lowered $\mathrm{pH}$.

Morphologically, it can be seen that as the HGE agent multiplies within the host cell, the phagosome membrane expands 


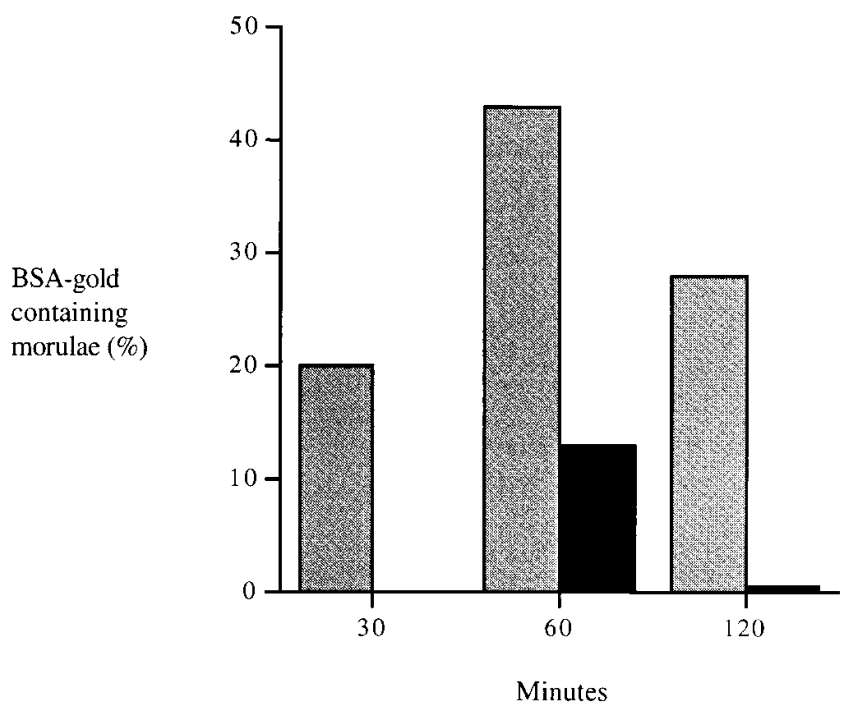

Figure 7. Percentage of HGE-containing vacuoles that also contained endocytosed BSA-gold. Thin sections of resin-embedded, infected HL-60 cells incubated in the presence of BSA-gold at $37^{\circ} \mathrm{C}$ (gray bars) and at $13^{\circ} \mathrm{C}$ (black bars), were sequentially sampled by transmission electron microscopy. HGE-containing vacuoles were examined for the presence or absence of BSA-gold particles and the results are expressed as a percentage of the total number of vacuoles (100) sampled.

to accommodate replicating organisms. The HGE bacteria take on two different forms inside the phagosome. The most obvious structure is spheroid with a loose cytoplasm. The other form has more irregular, angular profiles and electron opaque cytoplasm. The presence of these two distinct morphologies suggest similarities between the agent of HGE and other organisms, including the Chlamydiae. Chlamydiae exist as a small, metabolically inert, infectious particle (elementary body) and a larger, less electron opaque replicating stage (reticulate body). After replicating, the pathogen differentiates into elementary bodies to invade subsequent host cells. Upon cell entry Chlamydiae initially may enter the endocytic pathway (37), but do not remain in this compartment as demonstrated by lack of staining for endosomal and lysosomal markers $(38,39)$, and subsequently intersect with the exocytic pathway $(19,40)$.

Entry of HGE organisms into neutrophils may be depen-

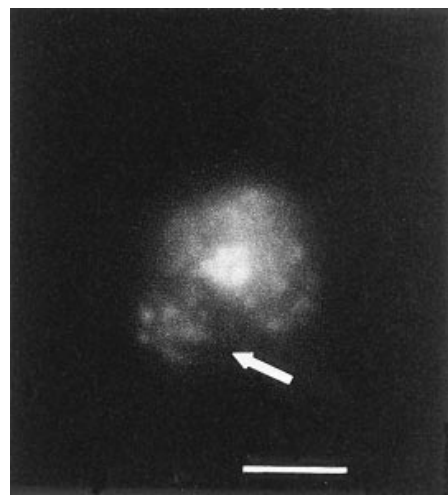

Figure 8. Micrograph of a HGE-infected HL-60 cell incubated in the presence of acridine orange and photographed under epi-fluorescent illumination. Acridine orange, which accumulates within the lumen of intracellular low $\mathrm{pH}$ compartments, will produce a fluorescent signal at sites of accumulation. In this micrograph, the signal is localized to many intracellular organelles and to individual particles of the

HGE agent (arrow). The lumen of the HGE vacuole is not fluorescent, indicating no accumulation of acridine orange. Bar, $10 \mu \mathrm{m}$.
A

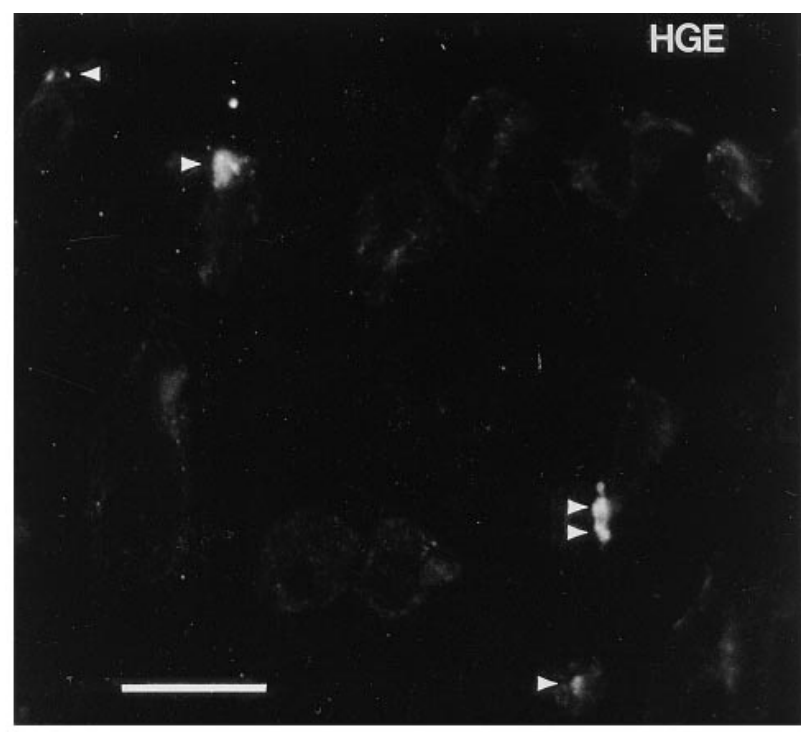

B

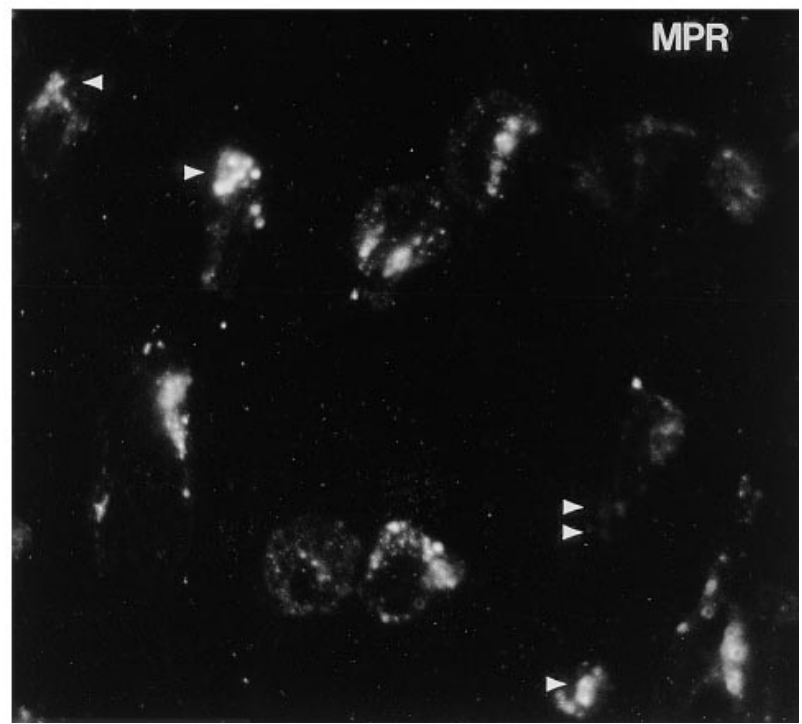

Figure 9. Indirect immunofluorescent labeled micrographs of a semithin section through Ehrlichia infected HL-60 cells. The section was labeled with anti-Ehrlichia and specific antibodies to MPR. $(A)$ The anti-Ehrlichia antibodies label the HGE organisms. $(B)$ Most of the labeled Ehrlichia, identified by comparing with the same field as the above micrograph, are also labeled with the anti-MPR (single arrow heads). However, one morula in the field is not labeled with antiMPR (double arrow heads). Scale bar, $50 \mu \mathrm{m}$.

dent on phagocytosis via a receptor-mediated mechanism of entry. Our observations of the tight association of some HGE bacteria to the host cell membrane suggest a receptor-ligand interaction as the initial stage of invasion. The lack of intimate contact of some of the HGE bacteria to the HL-60 cells, may be a normal occurrence when bacteria are suspended in a medium, since not all bacteria are expected to penetrate the host cell. Alternatively, it may also suggest that there are multiple uptake pathways. Anaplasma marginale, an intracellular pathogen that is also closely related to the agent of HGE, invades and multiplies inside erythrocytes $(41,42)$. Outer surface proteins of Anaplasma have been implicated in adhesion and entry (43). As another comparison, attachment of Chlamydiae is mediated by glycosaminoglycan-adhesin-ligand, bridging gly- 


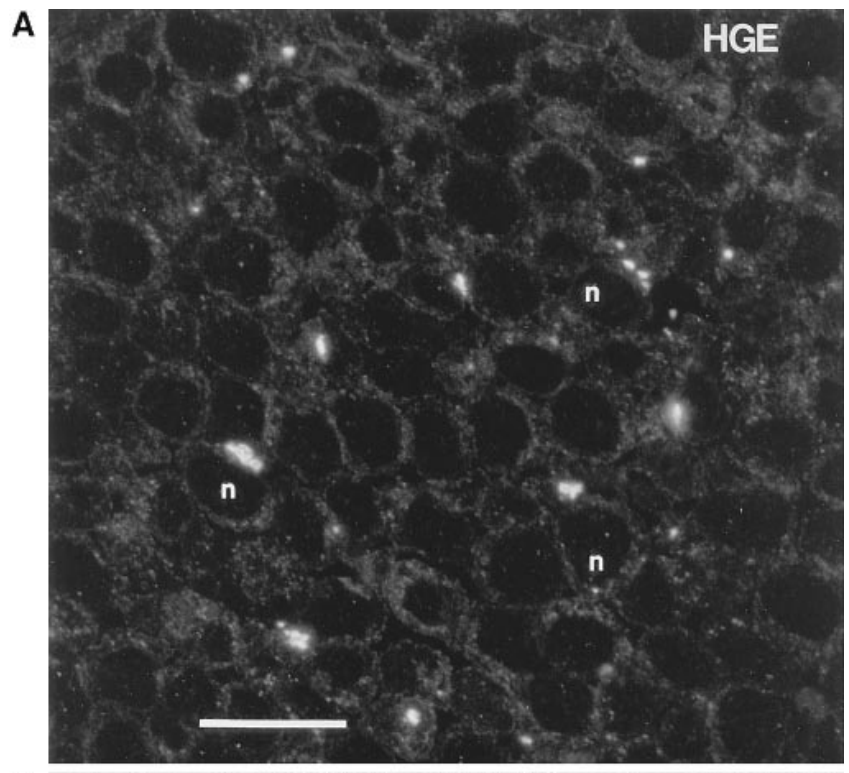

B

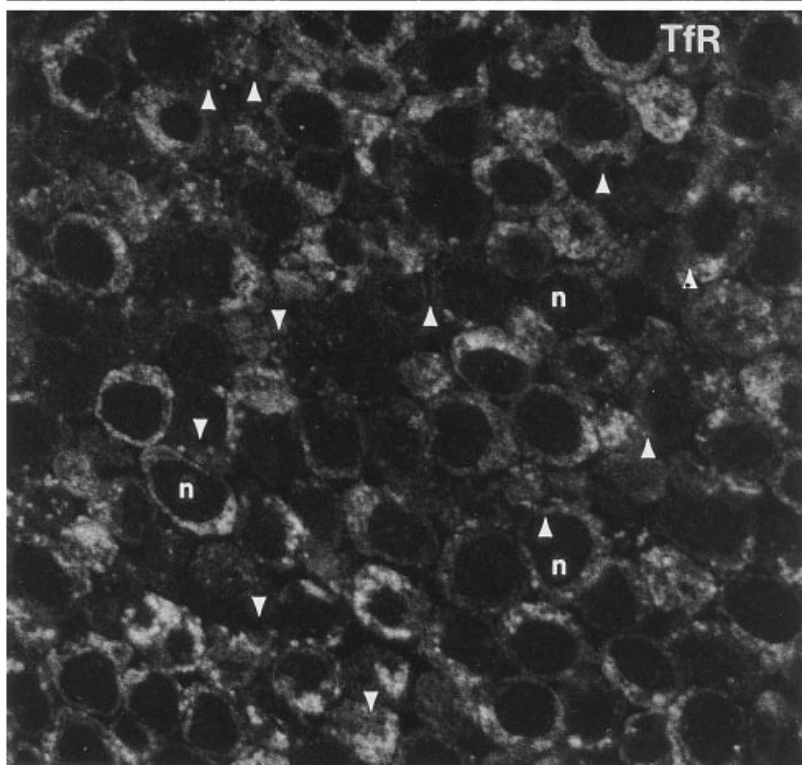

Figure 10. Indirect immunofluorescence labeled micrographs of semithin cryosections through Ehrlichia-infected HL-60 cells. The section was double labeled with antibodies to the HGE agent and TfR. (A) The specific anti-Ehrlichia antibodies identify the HGE organisms in the section. $(B)$ Anti-TfR does not colocalize with the anti-Ehrlichia signal (from $A$ ). Some nuclei have been labeled $(n)$, and arrowheads have been added to indicate the HGE bacteria, to aid orientation. Scale bar, $50 \mu \mathrm{m}$.

cosaminoglycan receptors on the host cell and the chlamydial surface (44). When Chlamydiae are taken up by host cells in this manner, rather than being phagocytosed, the organisms avoid uptake into the lysosomal pathway, and more readily persist. While these analogies with closely related organisms do not provide direct insight into the pathways used by HGE bacteria, our initial microscopic studies suggest that the entry of HGE bacteria into granulocytes may, at least in part, rely on a surface binding event.

Phagosomes have been shown to undergo maturation events that are associated with recycling of plasma membrane proteins and fusion with endosomal vesicles. This dynamic change of the phagosome leads to the addition of endosomal markers, the procurement of lysosomal glycoproteins, and finally to fusion with lysosomes $(15,45,46)$. We used markers of the endocytic pathway to characterize the intracellular vacuole containing the HGE agent, within HL-60 cells. The presence of BSA-gold particles inside vacuoles that contain the HGE bacteria is the most conclusive evidence to suggest that these morulae are part of the endocytic pathway. That the percentage of phagosome profiles containing endocytosed BSA-gold was maximal after $60 \mathrm{~min}$ incubation at $37^{\circ} \mathrm{C}$ and was reduced after 120 min incubation suggests that the $\mathrm{HGE}$ are in a late endosomal, prelysosomal compartment. This hypothesis is supported by the reduction in the percentage of BSA-gold positive phagosomes in cells that were incubated at $13^{\circ} \mathrm{C}$, a temperature that is known to inhibit early-late endosome fusion. The temperature block, by inhibiting delivery of the contents of early endosomes to late endosomes, would be expected to reduce BSA-gold delivery to Ehrlichia-containing phagosomes. The presence of MPR, a known marker of late endosomes, on the majority of the vacuole membranes further supports the endosomal nature of the vacuole. The absence of the transferrin receptor suggests that, unlike E. chaffeensis (25), the HGE agent is not accumulating in early endocytic compartments. The absence of LAMP 1 labeling suggests that the vacuole does not have the characteristics of compartments occurring later in the endocytic pathway, such as lysosomes. The morulae do not enter a lysosomal compartment, thereby avoiding a potential mechanism for intracellular killing.

Although we conclude that the HGE agent resides in a membrane-bound compartment with endosomal characteristics we cannot rule out the possibility that the organisms are also modifying the membranes of the enclosing organelle in some way. This possibility is suggested by the inability of the HGE-containing vacuole to accumulate DAMP. Normally, all parts of the endocytic pathway have lowered luminal $\mathrm{pH}$, with the organelles becoming more acidic further down the pathway. Organelles that contain MPR are usually considered to be part of the late endocytic pathway and should thus have a sufficiently lowered $\mathrm{pH}$ to accumulate DAMP. Either the HGE agent is modifying the vacuole membrane such that proton pumps are being excluded or inactivated, as occurs with $M$. tuberculosis (14), or the HGE agent is residing in a specialized, and as yet unidentified, part of the endocytic pathway. The MPR is involved with delivery of lysosomal enzymes to late endosomes and lysosomes and recycles from the Golgi apparatus to endosomal compartments and back again. We cannot exclude the possibility that the HGE agent is occupying part of the MPR recycling compartment. In addition, because the cultures are asynchronous, with cells that are newly invaded with HGE bacteria as well as cells that were infected earlier, newly invading HGE in vacuoles may not have matured sufficiently yet to accumulate MPR. This may account for the fact that only two thirds of the vacuoles are MPR-positive. Characterization of these differences within the HGE-containing compartment will undoubtedly be extended through further investigation.

This study provides a detailed examination of the HGEbacteria containing vacuole and demonstrates that the agent of HGE resides in the endocytic pathway. Information regarding the mechanisms that this unique pathogen uses to survive within host cells may lead to new strategies to treat this emerging infection. 


\section{Acknowledgments}

We thank Keith Joiner and Antony Sinai for critically reading the manuscript and for helpful discussions. We thank Ira Mellman (Yale University) and Bernard Hoflack (EMBL) for generously making antibodies to dinitro-phenol and mannose phosphate receptor available to us. The anti-LAMP 1 antibodies were obtained from the Developmental Studies Hybridoma Bank, University of Iowa, under contract NO1-HD-6-2915 from the NICHD.

This work was supported in part by the Centers for Disease Control (HR8/CCH113382-01) and the National Institues of Health (AI41440). J.W. IJdo is a Daland Fellow of the American Philosophical Society and is supported by a fellowship from the L.P. Markey Charitable Trust.

\section{References}

1. Bakken, J.S., J.S. Dumler, S.M. Chen, M.R. Eckman, L.L. Van Etta, and D.H. Walker. 1994. Human granulocytic ehrlichiosis in the upper midwest United States. A new species emerging? JAMA (J.Am. Med. Assoc.). 272:212-218.

2. Chen, S.M., J.S. Dumler, J.S. Bakken, and D.H. Walker. 1994. Identification of a granulocytotropic Ehrlichia species as the etiologic agent of human disease. J. Clin. Microbiol. 32:589-595.

3. Dawson, J.E., B.E. Anderson, D.B. Fishbein, J.L. Sanchez, C.S. Goldsmith, K.H. Wilson, and C.W. Duntley. 1991. Isolation and characterization of an Ehrlichia sp. from a patient diagnosed with human ehrlichiosis. J. Clin. Microbiol. 29:2741-2745.

4. Dumler, J.S., K.M. Asanovich, J.S. Bakken, P. Richter, R. Kimsey, and J.E. Madigan. 1995. Serologic cross-reactions among Ehrlichia equi, Ehrlichia phagocytophila, and human granulocytic ehrlichia. J. Clin. Microbiol. 33:10981103.

5. Johansson, K.E., B. Pettersson, M. Uhlen, A. Gunnarsson, M. Malmqvist, and E. Olsson. 1995. Identification of the causative agent of granulocytic ehrlichiosis in Swedish dogs and horses by direct solid phase sequencing of PCR products from the 16S rRNA gene. Res. Vet. Sci. 58:109-112.

6. Magnarelli, L.A., J.S. Dumler, J.F. Anderson, R.C. Johnson, and E. Fikrig. 1995. Coexistence of antibodies to tick-borne pathogens of babesiosis, ehrlichiosis, and Lyme borreliosis in human sera. J. Clin. Microbiol. 33:30543057.

7. Pierard, D., E. Levtchenko, J.E. Dawson, and S. Lauwers. 1995. Ehrlichiosis in Belgium. Lancet. 346:1233-1234.

8. Brouqui, P., J.S. Dumler, R. Lienhard, M. Brossard, and D. Raoult. 1995. Human granulocytic ehrlichiosis in Europe. Lancet. 346:782-783.

9. Reed, K.D., P.D. Mitchell, D.H. Persing, C.P. Kolbert, and V. Cameron. 1995. Transmission of human granulocytic ehrlichiosis. JAMA. (J. Am. Med. Assoc.). 273:23.

10. Goodman, J.L., C. Nelson, B. Vitale, J.E. Madigan, J.S. Dumler, T.J. Kurtti, and U.G. Munderloh. 1996. Direct cultivation of the causative agent of human granulocytic ehrlichiosis. N. Engl. J. Med. 334:209-215.

11. Theriot, J.A. 1995. The cell biology of infection by intracellular bacterial pathogens. Cell. Dev. Biol. 11:213-239.

12. Winkler, H.H. 1990. Rickettsia species (as organisms). Annu. Rev. Microbiol. 44:131-153.

13. Rabinovitch, M., and P.S. Veras. 1996. Cohabitation of Leishmania amazonensis and Coxiella burnetii. Trends Microbiol. 4:158-161.

14. Sturgill-Koszycki, S., P.H. Schlesinger, P. Chakraborty, P.L. Haddix, H.L. Collins, A.K. Fok, R.D. Allen, S.L. Gluck, J. Heuser, and D.G. Russell. 1994. Lack of acidification in Mycobacterium phagosomes produced by exclusion of the vesicular proton-ATPase. Science. 263:678-681.

15. Desjardins, M., L.A. Huber, R.G. Parton, and G. Griffiths. 1994. Biogenesis of phagolysosomes proceeds through a sequential series of interactions with the endocytic apparatus. J. Cell Biol. 124:677-688.

16. Sinai, A.P., and K.A. Joiner. 1997. Safe haven: the cell biology of nonfusogenic pathogen vacuoles. Annu. Rev. Microbiol. 51:415-462.

17. Clemens, D.L., and M.A. Horwitz. 1995. Characterization of the Mycobacterium tuberculosis phagosome and evidence that phagosomal maturation is inhibited. J. Exp. Med. 181:257-270.

18. Joiner, K.A., S.A. Fuhrman, H.M. Miettinen, L.H. Kasper, and I. Mellman. 1990. Toxoplasma gondii: fusion competence of parasitophorous vacuoles in Fc receptor-transfected fibroblasts. Science. 249:641-646.

19. Hackstadt, T., D.D. Rockey, R.A. Heinzen, and M.A. Scidmore. 1996. Chlamydia trachomatis interrupts an exocytic pathway to acquire endogenously synthesized sphingomyelin in transit from the Golgi apparatus to the plasma membrane. EMBO (Eur. Mol. Biol. Organ.) J. 15:964-977.

20. Scidmore, M.A., E.R. Fischer, and T. Hackstadt. 1996. Sphingolipids and glycoproteins are differentially trafficked to the Chlamydia trachomatis inclusion. J. Cell Biol. 134:363-374.

21. Andrews, N.W., C.K. Abrams, S.L. Slatin, and G. Griffiths. 1990. A T. cruzi-secreted protein immunologically related to the complement component C9: evidence for membrane pore-forming activity at low pH. Cell. 61:12771287.

22. Popov, V.L., S.M. Chen, H.M. Feng, and D.H. Walker. 1995. Ultrastructural variation of cultured Ehrlichia chaffeensis. J. Med. Microbiol. 43:411-421.

23. Kocan, K.M., D. Stiller, W.L. Goff, P.L. Claypool, W. Edwards, S.A Ewing, T.C. McGuire, J.A. Hair, and S.J. Barron. 1992. Development of Anaplasma marginale in male Dermacentor andersoni transferred from parasitemic to susceptible cattle. Am. J. Vet. Res. 53:499-507.

24. Wells, M.Y., and Y. Rikihisa. 1988. Lack of lysosomal fusion with phagosomes containing Ehrlichia risticii in P388D1 cells: abrogation of inhibition with oxytetracycline. Infect. Immun. 56:3209-3215.

25. Barnewall, R.E., Y. Rikihisa, and E.H. Lee. 1997. Ehrlichia chaffeensis inclusions are early endosomes which selectively accumulate transferrin receptor. Infect. Immun. 65:1455-1461.

26. Telford, S.R., III, J.E. Dawson, P. Katavolos, C.K. Warner, C.P. Kolbert, and D.H. Pershing. 1996. Perpetuation of the agent of human granulocytic ehrlichiosis in a deer tick-rodent cycle. Proc. Natl. Acad. Sci. USA. 93:62096214

27. Hanson, B.A., C.L. Wisseman, A. Waddell, and D.J. Silverman. 1981. Some characteristics of heavy and light bands of Rickettsia prowazekii on renografin gradients. Infect. Immun. 34:596-604.

28. Chen, S.M., J.S. Dumler, H.M. Feng, and D.H. Walker. 1994. Identification of the antigenic constituents of Ehrlichia chaffeensis. Am. J. Trop. Med. Hyg. 50:52-58.

29. Sun, W., J.W. IJdo, S.R. Telford III, E. Hodzic, Y. Zhang, S.W. Barthold, and E. Fikrig. 1997. Immunization against the agent of Human Granulocytic Ehrlichiosis in a murine model. J. Clin. Invest. 100:3014-3018.

30. Slot, J.W., and H.J. Geuze. 1981. Sizing of protein A-colloidal gold probes for immunoelectron microscopy. J. Cell Biol. 90:533-536.

31. Slot, J.W., and H.J. Geuze. 1985. A new method of preparing gold probes for multiple-labeling cytochemistry. Eur. J. Cell. Biol. 38:87-93.

32. Griffiths, G. 1993. Fine Structure Immunocytochemistry. Springer Verlag, Berlin. 275 pp.

33. Liou, W., H.J. Geuze, and J.W. Slot. 1996. Improving structural integrity of cryosections for immunogold labeling. Histochem. Cell Biol. 106:41-58.

34. Anderson, R.G., J.R. Falck, J.L. Goldstein, and M.S. Brown. 1984. Visualization of acidic organelles in intact cells by electron microscopy. Proc. Natl. Acad. Sci. USA. 81:4838-4842.

35. Mayhew, T.M., and H.J. Gundersen. 1996. If you assume, you can make an ass out of $u$ and me: a decade of the disector for stereological counting of particles in 3D space. J. Anat. 188:1-15.

36. Weibel, E. 1979. Practical Methods for Biological Morphometry. Stereological Methods. Vol. 1. Academic Press, New York. 193 pp.

37. Scidmore, M.A., D.D. Rockey, E.R. Fischer, R.A. Heinzen, and T. Hackstadt. 1996. Vesicular interactions of the Chlamydia trachomatis inclusion are determined by chlamydial early protein synthesis rather than route of entry. Infect. Immun. 64:5366-5377.

38. Heinzen, R.A., M.A. Scidmore, D.D. Rockey, and T. Hackstadt. 1996. Differential interaction with endocytic and exocytic pathways distinguish parasitophorous vacuoles of Coxiella burnetii and Chlamydia trachomatis. Infect. Immun. 64:796-809.

39. Taraska, T., D.M. Ward, R.S. Ajioka, P.B. Wyrick, S.R. Davis-Kaplan, C.H. Davis, and J. Kaplan. 1996. The late chlamydial inclusion membrane is not derived from the endocytic pathway and is relatively deficient in host proteins. Infect. Immun. 64:3713-3727.

40. Hackstadt, T., M.A. Scidmore, and D.D. Rockey. 1995. Lipid metabolism in Chlamydia trachomatis-infected cells: directed trafficking of Golgiderived sphingolipids to the chlamydial inclusion. Proc. Natl. Acad. Sci. USA. 92:4877-4881

41. Ristic, M. 1968. Anaplasmosis. In Infectious Blood Diseases of Man and Animals. D. Weinman and M. Ristic, editors. Academic Press, Inc., New York. 478-572.

42. Weisburg, W.G., S.M. Barns, D.A. Pelletier, and D.J. Lane. 1991. 16S ribosomal DNA amplification for phylogenetic study. J. Bacteriol. 173:697-703.

43. McGarey, D.J., A.F. Barbet, G.H. Palmer, T.C. McGuire, and D.R. Allred. 1994. Putative adhesins of Anaplasma marginale: major surface polypeptides 1a and 1b. Infect. Immun. 62:4594-4601.

44. Zhang, J.P., and R.S. Stephens. 1992. Mechanism of Chlamydia trachomatis attachment to eukaryotic host cells. Cell. 69:861-869.

45. Pitt, A., L.S. Mayorga, P.D. Stahl, and A.L. Schwartz. 1992. Alterations in the protein composition of maturing phagosomes. J. Clin. Invest. 90:19781983.

46. Pitt, A., L.S. Mayorga, A.L. Schwartz, and P.D. Stahl. 1992. Transport of phagosomal components to an endosomal compartment. J. Biol. Chem. 267: 126-132. 